\title{
Aetiology of idiopathic growth hormone deficiency in England and Wales
}

\author{
R. J. RONA* AND J. M. TANNER
}

From the Department of Growth and Development, Institute of Child Health, University of London

SUMMARY Information on height, sex, age, and condition of mothers' pregnancy and labour was obtained on all first- and second-degree relatives of 140 cases of idiopathic growth hormone deficiency (GHD). Less detailed information was available for 68 further cases, the two samples together constituting all cases from England and Wales treated under the Medical Research Council Clinical Trial of Human Growth Hormone up till 1974. Compared with the Perinatal Mortality survey of 1958, idiopathic GHD cases showed a significantly greater incidence of breech births $(13 \cdot 7 \%)$, of forceps deliveries especially in multiparae $(5 \cdot 6 \%)$, and of reported early vaginal bleeding $(7 \cdot 1 \%)$. The incidences of breech and forceps were both higher in cases with multiple pituitary hormone deficiency than in cases of 'isolated' GHD. The frequency of either breech or forceps was $43 \%$ in multiple and $20 \%$ in 'isolated' GHD. Heights of fathers and sibs of affected cases averaged the 50 th centile; those of mothers the 35 th centile.

The ratio of boys to girls affected was $3 \cdot 8$. There were 4 families with more than one member affected; $4.5 \%$ of the brothers of probands were themselves affected, $2 \%$ of fathers and $1.5 \%$ of both sisters and mothers. In the world literature the sex ratio averages about 2.9 with little difference between series; the frequency of breech delivery averages $21 \%$ with large differences $(2 \%$ to $50 \%)$ between series. A table of relative risks is given from which a screening procedure may be constructed; following $1 \%$ of selected births would give $10 \%$ of cases, and $20 \%$ of births $50 \%$ of cases.

We propose a multifactorial aetiology for GHD which brings it into line with malformations such as anencephaly, cleft lip and palate, and pyloric stenosis. An underlying liability to the disease is postulated, continuously distributed in the population and depending on both polygenic and environmental factors among which sex and birth trauma are important. The disease becomes manifest when the liability value reaches a fixed threshold. On this assumption, heritability of idiopathic GHD is approximately the same as that of coeliac disease, pyloric stenosis, and patent ductus.

Idiopathic growth hormone deficiency (GHD), as its name indicates, is a disorder or group of disorders of uncertain aetiology. At first regarded as a disorder of the pituitary gland, it is now thought usually or always to follow degeneration of parts of the hypophysiotrophic area of the hypothalamus or of higher locations in the central nervous system. The reason for the degeneration is unknown, though a number of authors (Prader, 1960; Prader et al., 1967; Bailey et al., 1967; Hubble, 1967; Bierich, 1972) have noted an association with an abnormal labour. On the other hand, the occurrence of familial cases unassociated with abnormal labour is well known.

\section{Received 15 June 1976}

*Present address: Department of Community Medicine, St. Thomas's Hospital, London SE1.
We have conducted a survey, therefore, into the family and birth histories of some 200 cases. The results lead us to propose an aetiology of a similar nature to that applying to pyloric stenosis or spina bifida: a polygenically-controlled susceptibility, with a liability to develop the disease importantly affected both by sex and by events at birth or during pregnancy.

\section{Subjects and methods}

Samples. The main sample of patients, totalling 164 , consisted of 133 cases from the Growth Disorder Clinic of The Hospital for Sick Children, London; 16 from the Childrens Hospital, Birmingham; and 15 from the Royal Victoria Infirmary, Newcastle upon Tyne. We are greatly indebted to Drs. Paul 
Rayner and Michael Parkin for furnishing us with the details on the last two sets of patients.

A questionnaire (Rona, 1976) was given to all parents of the main sample, requesting detailed information for each child of the sibship on sex, birthweight, length of gestation, complications of pregnancy and labour, malformations, age, and present height. Occupation, place of birth, consanguinity, illnesses, and height were asked concering the parents, uncles, aunts, and grandparents. The number of children born to each uncle or aunt was noted and inquiry made as to whether any were thought to be of short stature. Details of short stature among the sibs of the grandparents were requested and information on the number of stillborns, miscarriages, and medical terminations experienced by the mother. $86 \%$ of these questionnaires were returned, most without apparent error. Personal discussions followed with all Hospital for Sick Children parents whose questionnaires raised problems, and eventually only one set of answers was rejected as inaccurate. Some information was necessarily incomplete due to divorce, early death of grandparents, uncles, etc. However, in all cases the information on the proband's sibship was complete. This $86 \%$ of the main sample who returned questionnaires is called the definitive sample and numbered 140 cases (see Table 1).

Table 1 Samples studied

\begin{tabular}{lrr}
\hline Sample & No. & \\
\hline $\begin{array}{l}\text { Main } \\
\text { (London, Birmingham, Newcastle) }\end{array}$ & 164 & \\
$\begin{array}{l}\text { Definitive } \\
\text { (questionnaires returned) }\end{array}$ & 140 \\
$\begin{array}{l}\text { 'Isolated', GHD } \\
\text { 'Multiple' PHD }\end{array}$ & 119 & \\
$\begin{array}{l}\text { Supplementary } \\
\text { (a) From main sample, } \\
\text { questionaires missing }\end{array}$ & 21 & \\
(b) From other UK clinics & 24 & \\
Total & 44 & \\
\hline
\end{tabular}

The children of the main sample were drawn from all parts of England and Wales, and represented $79 \%$ of all cases of idiopathic GHD reported in this area up till the end of 1973 and accepted for treatment in the Medical Research Council Clinical Trial of Human Growth Hormone (see Tanner et al., 1971, for details). Data regarding some items such as sex, birth order, and method of delivery were available for the remaining $21 \%$ of cases, and kindly supplied to us by Dr. Michael Preece, Medical Co-ordinator of the trial. We have added these cases to the 24 cases of the main sample whose questionnaires were not returned to make a supplementary sample consisting in all of 68 cases. Thus the total notified cases are subdivided into definitive (140) and supplementary (68) samples.

In a case-control study of this kind it is of prime importance to know whether the affected cases represent a true sample of the population at risk, since the incidence of such things as breech delivery in the affected is to be compared with the incidence in the general population. We can test for differences between definitive and supplementary samples in a few items. The percentage of males in the definitive sample was $80 \%$ and in the supplementary sample $78 \%$. The percentage of cases who were first borns did not differ significantly, being $49 \%$ in the definitive sample and $45 \%$ in the supplementary. It is therefore likely that our definitive sample represents well the totality of cases of idiopathic GHD notified in England and Wales up to the end of 1973. This is not to say that it truly represents all actual cases, since it is possible that the chances of a given case being notified or diagnosed varies between different parts of the country. The parents themselves, however, do represent a fairly good sample of the population of England and Wales as judged by their birthplaces. Of the $89 \%$ born in England and Wales, $22 \%$ were born in the North-west, $19 \%$ in the Midlands, $52 \%$ in London and the South, and 7\% in Wales. Equivalent figures for all persons in 1936 were $32 \%, 22 \%, 40 \%$, and $6 \%$. Thus though there is a significant preponderance of London- and Southborn among parents, the other parts of the country are well represented.

Diagnosis. Among cases referred for treatment with human growth hormone about a quarter to a third have deficiencies secondary to a defined organic lesion, frequently a craniopharyngioma. The remainder have idiopathic GHD. In this series no child was included who had specific neurological signs or a primary specific diagnosis.

Children with idiopathic GHD may have (i) true isolated GHD; all other pituitary functions are normal and puberty occurs normally, at a normal bone age though a late chronological age (Tanner and Whitehouse, 1975); (ii) GHD plus gonadotrophin deficiency; other pituitary functions are normal; (iii) GHD plus deficiencies of thyroid stimulating hormone (TSH), and/or ACTH (whether or not with deficiency of gonadotrophins, though lack is usual). It is now not possible to distinguish categories (i) and (ii) before puberty; in consequence we combine them into a single category called 'isolated' GHD (IGHD), the apostrophes serving to remind the reader that gonadotrophin deficiency may yet manifest itself as the child gets older. Among cases in the London series who have reached an age where 
distinction is possible, about four-fifths represent true isolated GHD; one-fifth have added gonadotrophin deficiency (Tanner and Whitehouse, 1975). The second category we call here multiple pituitary hormone deficiency (MPHD), without distinction as to whether the lack is of TSH, ACTH, or both.

The ratio of multiple to 'isolated' cases varies very much from investigator to investigator. This is partly due to the criteria used for diagnosis of TSH and ACTH deficiency. In our cases TSH deficiency was investigated at first by serum protein-bound iodine concentration, later by $\mathrm{TSH}$, thyroxine, and triiodothyronine levels and usually a thyrotropinreleasing hormone test. In our definitive sample 15 cases had TSH deficiency (11\%), (including 1 who developed it during treatment). ACTH deficiency was tested initially by the increase in excretion of hydroxycorticoids after daily administration of 20 units tetracosatrin for 3 days, and since 1970 by the response of blood cortisol in a valid insulin hypoglycaemia test (see below). Only 9 of our definitive sample $(6 \%)$ had ACTH deficiency. Thus our sample (Table 1) is divided into 94 boys and 25 girls (total 119 cases) with IGHD and 19 boys and 3 girls (total 21 cases) with MPHD.

Growth hormone deficiency was in all cases diagnosed on both auxological and biochemical criteria, both requiring to be met. For 'complete' deficiency the height growth velocity had to be lower than 2 SDs below the mean for chronological age (or bone age, over 10 years), assessed over a full year with quarterly measurements of height by skilled personnel using modern instruments. On treatment with human growth hormone the velocity had to increase during the first year by more than $2 \mathrm{~cm} / \mathrm{yr}$. Biochemically the insulin hypoglycaemia test was used, and the peak level of growth hormone in a valid test was required to be below $7 \mathrm{mU} / \mathrm{l}$. For 'partial' deficiency the peak growth hormone value had to be between 7 and $19 \mathrm{mU} / 1$ inclusive, and the standard deviation score (SDS) for height velocity between $-1 \cdot 0$ and $-2 \cdot 0$. First-year treatment velocity had still to be $2 \mathrm{~cm} / \mathrm{yr}$ more than pretreatment velocity. No mention of absolute height enters into these criteria since it is in principle possible to diagnose and treat a case before he or she has fallen below the 3rd centile for height attained; however, in practice this applies mainly to secondary cases and all cases in the present series were 3 SD or more below the mean height for age. Only 7 cases came into the category of partial deficiency, so total and partial deficiencies have been throughout considered together.

Characteristics. The age of the patients at referral ranged from 1.5 to 20 years, with one exception aged $30.78 \%$ were aged less than 12.5 years. There was no significant sex difference in age at referral. The mean height was $-4 \cdot 5$ SDS with SD $1 \cdot 2$. The mean bone age (Tanner-Whitehouse Method 1, $1975)$ averaged $-3 \cdot 2$ SDS. There was no significant difference in height between cases of IGHD and MPHD.

Control population. Two populations were used for comparison with the affected cases. The first was the Perinatal Mortality Survey of 1958 (Butler and Bonham, 1963; Butler and Alberman, 1969). This gives complete information about the factors in which we were interested, but the data refer to 1958, whereas the average date of birth of our cases was 1965 . For this reason we have also used the more limited information in the Registrar-General's Statistical Review of England and Wales in relevant years concerning age distribution of mother and father at time of delivery, season of delivery, infant mortality, and parity of mother. In addition some comparisons have been made with the 1970 British Births Survey (Chamberlain, 1975).

Classification of spontaneous delivery, assisted breech (all breech deliveries), forceps, stillbirths, miscarriages, etc, follow the usage of the Perinatal Mortality Survey. The occupation of the chief economic supporter of the family (as used in the 1971 census) was listed by Registrar-General's classification of 1970 and was available for $94 \%$ of families.

Statistical methods. Correction for continuity was made in all $\chi^{2}$ tests from $2 \times 2$ tables. Where there were less than 5 cases in a cell both $\chi^{2}$ and the confidence limits for a Poisson distribution of the variable in the population were used (Pearson and Hartley, 1966) under the assumption that cases of idiopathic GHD were a subsample of the English population. In testing seasonal variation in incidence the Edwards (1961-62) test was preferred to simple $\chi^{2}$ with 11 degrees of freedom, with and without the modification suggested by Walter and Elwood, (1975).

Genetical methods. As a test of whether the disorder was caused by a single autosomal gene we compared the distributions of affected members in the sibships with those expected from theory (the a priori method, Neel and Schull, 1954). The probability of a given affected child having further affected sibs was calculated by Weinberg's proband method, as presented by Crow (1965, pp. 26-30).

Relative risk. A measure of the degree to which a factor under study (such as breech birth) is associated 
with a child being affected was calculated as the relative liability or risk, defined by Edwards (1958). The relative risk is given by $a d / b c$ where $a, b, c, d$ are the values in a two by two table classifying affected/ nonaffected versus exposed/nonexposed. The value $a$ is affected/exposed, $b$ nonaffected/exposed, $c$ affected/nonexposed, $d$ nonaffected/nonexposed. Correction for continuity was made. Confidence limits were calculated following Fleiss (1973).

\section{Results}

Seasonal variation in birth. In neither the IGHD nor the MPHD cases was there a significant departure from the control population in distribution of months of birth, using Edwards (1961-62) and Walter and Elwood (1975) tests. The probabilities approximated $50 \%$. The control population was the average of births in 1955, 1960, and 1965.

Social class. There were slightly more parents in classes I and II than in the general population and slightly fewer in classes IV and V. The differences approached but did not quite reach the $5 \%$ level of significance. The difference is easily accounted for by differential likelihood of referral, especially since in quite a few cases it was the parents who urged referral on reluctant doctors and not vice versa.

Parental age. The ages of mothers and fathers at the time of delivery of the affected child averaged 26.9 and 30.9 years, respectively, with SDS of 5.6 and 6.5 years. The control population of 1958 gave means of $27 \cdot 2$ and $30 \cdot 5$; the average of the RegistrarGeneral Reports for 1963 and 1969 (Great Britain. General Register Office, 1963, 1969) gave means of $27 \cdot 9$ and $29 \cdot 9$. There was a significant disagreement between the distributions of maternal ages at patients' birth in the sample and the 1958 survey, but this disappeared when parity was taken into account. A high proportion of affected were first-borns (see below), and comparison of ages of primiparae and multiparae separately showed no significant differences. The match with the 1963-1969 means was even closer. No significant differences were apparent between the IGHD and MPHD cases.

Sex ratio. The ratio of boys to girls was $4 \cdot 1$ in the definitive sample and 3.8 for the total of definitive plus supplementary samples. There was no significant difference in sex ratio between IGHD and MPHD cases. The sex ratio in the sibships of the affected patients was $1 \cdot 06$, which agrees with that of the population of England and Wales under 20 years old, which is 1.05 .

Parity. Two comparisons were made using the definitive sample. First, the parity of mothers at the birth of the affected child was compared with the population distributions for 1958 (Butler and Bonham, 1963) and for 1967-71 (Great Britain. General Register Office, 1971). The result is shown in Table 2. The excess of first borns is considerable and $x^{2}$ comparing first born and later-born affected against first-born and later-born in the 1958 sample was $8.5(\mathrm{P}<0.01)$, and in the 1967-71 figures was $6 \cdot 8(\mathrm{P}<0.01)$. The relative risk amounted to 1.6 for first-born compared with later-born. The relationship was similar in both IGHD and MPHD groups. This information was available for the supplementary sample also. The same result was obtained: $45 \%$ of the supplementary sample were first-born compared with $49 \%$ of the definitive sample.

The second test compared the observed distribution of affected cases with the theoretical distribution of an affected individual having equal probability of being born in each of the birth orders represented in his sibship (MacMahon and Pugh, 1971). Sibships with more than one affected, and twins, were omitted. The comparison between first-born and later-born was again significant $(\mathrm{P}<0.05)$, whereas heterogeneity among later-born was not (Rona, 1976).

Complications during pregnancy and delivery. The incidence of perinatal deaths and of miscarriages in families of the affected cases did not differ signifi-

Table 2 Distribution of the mothers of the affected children according to the number of previous liveborn children (definitive sample)

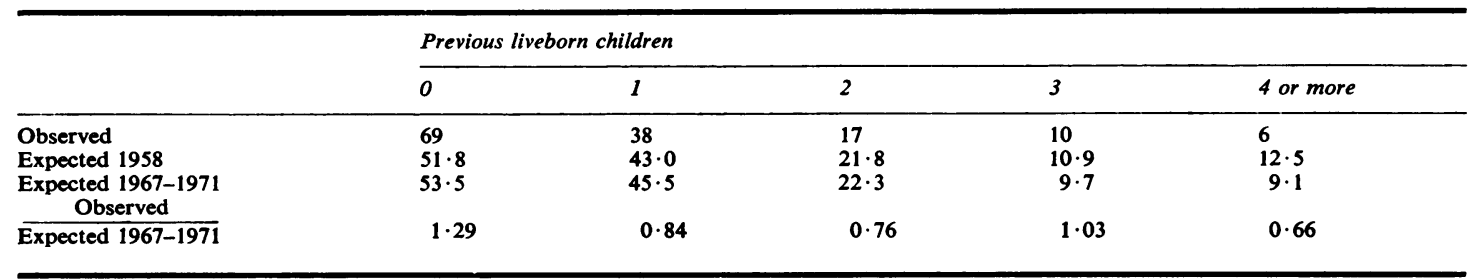


cantly from those in the control populations. The incidence of reported vaginal bleeding during pregnancy (mostly before the 28th week) was high, being $7.1 \%$ in the definitive sample, compared with $3.0 \%$ in the Perinatal Mortality Survey of 1958. This difference is highly significant $(P<0.01)$. The relative risk to a mother having early vaginal bleeding of bearing an affected child was 2.6. The incidence of eclampsia, however, was not increased over that in the control population. There were 3 malformations, an incidence of $2 \cdot 1 \%$.

Table 3 shows the frequency of each type of delivery in the definitive sample. The figures for assisted breech and for forceps are much increased over expectation, whereas those for caesarean section are not. In no less than $11.4 \%$ of the cases delivery was by assisted breech which gives a relative risk of 5.9 for an infant born this way of developing the disorder. Type of delivery was recorded in the supplementary sample also, though the information may be less accurate. In fact, Table 4 shows that there was good agreement with the definitive sample, the incidence of breech delivery being even higher, though not significantly so. In the two samples combined the incidence was $13.7 \%$ with a relative risk of 7.2. The $\chi^{2}$ for breech versus all other methods of delivery was $53.2(P<0.001)$ in comparison with the Perinatal Mortality Survey of 1958 , in which the incidence of breech was $2 \cdot 2 \%$. Breech delivery is more frequent in first-born $(2.5 \%)$ than in later-born $(1.9 \%)$ but allowing for this did not alter the strength of the relationship between breech delivery and idiopathic GHD (Table 5). When the cases were divided into those with IGHD and those with MPHD the incidence was higher in the MPHD cases $(19 \cdot 0 \pm 8 \cdot 5 \%)$ than in the IGHD cases $(10 \cdot 2 \pm 2 \cdot 8 \%)$, though the difference was not significant. The result could be taken as evidence that the two conditions are similar, with MPHD being a more severe stage of the disorder.

The frequency of forceps delivery was also greater than expected, being $12.1 \%$ in the definitive sample and $10.7 \%$ in the combined definitive and supplementary samples, compared with $4.7 \%$ in the 1958 survey and $7.9 \%$ in the 1970 survey. $\chi^{2}$ for the definitive sample compared with the 1965 value interpolated between the two surveys was 7/2.
Table 4 Method of delivery of affected children (supplementary sample)

\begin{tabular}{lrr}
\hline Method of delivery & $n$ & $\%$ \\
\hline Assisted breech & 11 & $19 \cdot 3$ \\
Caesarean section & 3 & $5 \cdot 3$ \\
Forceps & 4 & $7 \cdot 0$ \\
Spontaneous vertex & 39 & $68 \cdot 4$ \\
Lack of information & 11 & \\
\hline
\end{tabular}

Table 5 Frequency of breech and forceps deliveries according to parity of the mother

\begin{tabular}{|c|c|c|c|c|}
\hline & \multicolumn{2}{|c|}{ Primiparae affected: } & \multicolumn{2}{|c|}{ Multiparae affected: } \\
\hline & Yes & No & Yes & No \\
\hline $\begin{array}{l}\text { Breech } \\
\text { Yes } \\
\text { No } \\
\text { Total no. }\end{array}$ & $\begin{array}{l}13 \cdot 0 \% \\
87 \cdot 0 \% \\
69\end{array}$ & $\begin{array}{r}2 \cdot 45 \% \\
97 \cdot 55 \%\end{array}$ & $\begin{array}{l}9 \cdot 9 \% \\
91 \cdot 1 \% \\
71\end{array}$ & $\begin{array}{r}1 \cdot 9 \% \\
98 \cdot 1 \%\end{array}$ \\
\hline $\begin{array}{l}\text { Forceps } \\
\text { Yes } \\
\text { No } \\
\text { Total no. }\end{array}$ & $\begin{array}{l}18 \cdot 8 \% \\
81 \cdot 2 \% \\
69\end{array}$ & $\begin{array}{l}10 \cdot 5 \% \\
89 \cdot 5 \%\end{array}$ & $\begin{array}{l}5 \cdot 6 \% \\
94 \cdot 4 \% \\
71\end{array}$ & $\begin{array}{r}1 \cdot 2 \% \\
98 \cdot 8 \%\end{array}$ \\
\hline
\end{tabular}

Forceps is much more commonly used in primiparae $(10.5 \%$ in the 1958 data) than in multiparae $(1.2 \%)$, so that comparisons are better made within these two categories. The figures are given in Table 5. The relationship between forceps delivery and having an affected child was stronger for multiparae than primiparae, though present in both. As in breech delivery the cases of MPHD had a higher incidence of forceps delivery $(24 \% \pm 9 \%)$ than the cases of IGHD $(10 \% \pm 3 \%)$ though the difference was not significant.

The frequency of occurrence of either breech delivery or forceps was $42.9 \%$ in MPHD and $20.2 \%$ in IGHD. This difference, tested on the absolute numbers, gave a significant $\chi^{2}$ value (3.92, $\left.\mathrm{P}<0 \cdot 05\right)$. The excess of breech deliveries occurred equally in affected males and females, with risk ratios of 5.7 and 6.7 in boys and girls, respectively. For forceps delivery the risk ratios were $2 \cdot 1$ and $4 \cdot 0$ for girls and boys; the difference however is not significant.

Unaffected sibs. The unaffected sibs, considered as a control group, showed similar frequencies of breech delivery $(2 \cdot 3 \%)$ and vaginal bleeding $(4 \cdot 2 \%)$ to those of the 1958 control population, and a somewhat lower frequency of forceps delivery $(1.9 \%)$.

Table 3 Method of delivery of affected children (definitive sample)

\begin{tabular}{lrrrr}
\hline Method of delivery & $n$ & $\%$ & Expected 1958 \\
\hline Assisted breech & 16 & $11 \cdot 4$ & $3 \cdot 0$ & Relative risk \\
Forceps & 17 & $12 \cdot 1$ & $6 \cdot 5$ & $5 \cdot 9$ \\
Caesarean section & 5 & $6 \cdot 6$ & $3 \cdot 7$ & $1 \cdot 4$ \\
Spontaneous vertex & 102 & $72 \cdot 8$ & $126 \cdot 7$ & $0 \cdot 3$ \\
\hline
\end{tabular}


Birthweight. The mean birthweight was $3378 \mathrm{~g}$, SD 574. When corrected for parity, length of gestation, and height of mother (Tanner and Thompson, 1970) the SDS, relative to the Aberdeen standards, was $-0 \cdot 17 \pm 0 \cdot 08$. The mean for the breech deliveries was $2883 \mathrm{~g}$, SD 738 and the distribution of these weights did not differ significantly from that of breech births in the 1958 control population. When breech deliveries were omitted the mean SDS of the affected infants' birthweights was $-0 \cdot 15 \pm 0 \cdot 08$. The general population mean is a little below that of the Aberdeen children (see Tanner et al., 1975). Thus there is no significant difference between the birthweight of affected children, delivered either by vertex or breech and similarly delivered control children. The figures for the supplementary sample were in close agreement.

Familial data. Table 6 shows the frequency of pathological short stature among relatives of the probands, using both definitive and supplementary samples. The 6 brothers and 2 sisters were known to have IGHD as were 3 out of the 4 reported fathers ( 2 of these were reported by Poskitt and Rayner, 1975). The remaining relatives reported were not examined biochemically, but only reported as having stature less than $145 \mathrm{~cm}$ without any disproportion or disability. The information on sibs was complete and reliable; all cases where any doubt existed were examined by us. After elimination of those suffering only from arithmetic error there were 6 sibs with short stature and all had normal responses to insulin hypoglycaemia. 2 of them had delayed puberty and soon began their adolescent growth spurt, 1 had Silver-Russell syndrome, 2 simple genetic shortness (1st centile), and 1 remained undiagnosed. Short stature was reported in 8 cousins, but height was checked on 5 of them and was within normal limits in each case. Three uncles reported short were likewise actually normal. Thus no new confirmed cases were shown by the questionnaires; all 3 mothers were part of the supplementary sample and their data should be treated with reserve.

There were four sibships in which more than 1 sib was affected ( 2 pairs of brothers and 2 mixed pairs). In one of these sibships the father was also affected. In two other families the father and a single sib were affected. Probably there were 1 further affected father and 3 affected mothers, but these were unconfirmed by insulin tolerance tests. The proportions of uncles, aunts, and cousins affected were much smaller. The probability of an affected child having an affected sib was $1 \cdot 7 \pm 0 \cdot 8 \%$.

Only $3 \%$ of the sibships studied had more than one affected child, and about $80 \%$ were probably completed sibships, in that the mothers were aged over 35 . This low percentage makes any single-locus inheritance extremely unlikely. The hypothesis of single-locus autosomal recessive inheritance was tested by the $a$ priori method (Rona, 1976). According to the hypothesis, $161 \pm 6$ cases would be expected in the definitive sample, and only 126 were present, a value which lies far outside the confidence limits of the expected range. The same result was obtained when the IGHD cases only were considered. Recessive sex-linked inheritance and dominant autosomal inheritance were incompatible with genealogical analysis. As regards consanguinity, there was only one cousin marriage among the whole sample.

Twins. There were two pairs of twins in the series. One pair, with a probability of 0.998 of being monozygotic, were males of whom only one was affected (cf. Rosenbloom and Smith, 1965). In the other pair, of unlike sex, the girl had IGHD and the boy not.

Table 7 Height distribution for first-degree relatives (definitive sample)

\begin{tabular}{lcll}
\hline Kinship & $n$ & Mean & $S D$ \\
\hline $\begin{array}{l}\text { Mother } \\
\text { (estimated height) }\end{array}$ & 138 & 160.7 & 5.92 \\
$\begin{array}{l}\text { Mother } \\
\text { (measured height) }\end{array}$ & 38 & 159.8 & 6.62 \\
$\begin{array}{c}\text { Father } \\
\text { (estimated height) }\end{array}$ & 138 & 174.2 & $7 \cdot 13$ \\
$\begin{array}{c}\text { Brother } \\
\text { (estimated height) }\end{array}$ & 75 & $-0.06^{*}$ & $0.96^{*}$ \\
$\begin{array}{c}\text { Sister } \\
\text { (estimated height) }\end{array}$ & 82 & $0.01^{*}$ & $0.96^{*}$ \\
\hline
\end{tabular}

*Estimated as standard deviation score for age, the mean of the unaffected sibs in each sibship being used.

Table 6 Idiopathic GHD in relatives of affected (definitive and supplementary samples)

\begin{tabular}{llllr}
\hline Kinship & No. proved & No. not proved & No. of relatives \\
\hline Brother & 6 & - & 133 & Percentage affected \\
Sister & 2 & - & 125 & $4 \cdot 5$ \\
Father & 3 & 1 & 194 & $1 \cdot 6$ \\
Mother & 0 & 2 & 194 & $1 \cdot 6$ \\
Uncle/aunt & 0 & 3 & 686 & $0 \cdot 3$ \\
Cousin & 0 & 235 & $0 \cdot 2$ \\
\hline
\end{tabular}

*See text. 
Heights of relatives. Table 7 shows the reported heights of first-degree relatives in the definitive sample together with a comparison with height measurements in the growth clinic for 38 mothers. The mean height of fathers was exactly at the 50th centile for British standards (Tanner, et al., 1966), as were the heights of brothers and sisters. The mothers' average height lay at about the 35 th centile of the standards. The average heights of the supplementary sample parents were similar, being $173 \cdot 8$ and $161.9 \mathrm{~cm}$.

\section{Discussion}

This study is the largest investigation to date on the epidemiology of idiopathic growth hormone deficiency, Not only have 140 cases (the definitive sample) been studied in detail, a certain amount is known about the 68 further cases (supplementary sample) which together with the 140 constitute the entire population of all cases in England and Wales notified to the Medical Research Council Trial of Human Growth Hormone from 1959 to 1974. Thus for such items as sex, birth order, and breech delivery the information is complete. Furthermore, in no item tested did the two samples differ, so we may assume that the definitive sample represents well the whole population of cases notified. Whether the cases notified represent all cases present in the child population is of course doubtful, but at least patients were drawn from all over England and Wales. Since we are comparing the incidence of various events in our affected population with the incidence in the national population represented by the Perinatal Mortality Survey of 1958 supplemented by the Registrar-General's Statistical Reviews, the way in which our sample of cases was drawn is of cardinal importance.

The diagnoses of the cases in both samples were established firmly, not only by the paediatricians involved but by reference, in every case, to the Working Party of the Medical Research Council Trial, which applied stringent criteria for accepting cases as suitable for human growth hormone treatment. All cases have been treated successfully with growth hormone and most have been followed for over 4 years. Only 7 cases of partial GHD have been included, and these all responded to growth hormone with good catch-up velocities.

The relative proportion of IGHD to MPHD cases varies greatly from one series to another. In England and Wales the ratio was 5.7 and this is the highest proportion of isolated cases reported. In the San Francisco study the ratio was $3 \cdot 8$ (Kaplan et al., 1974), in the Canadian series 1.4 (Guyda et al., 1975), in Zurich 1.7 (Prader et al., 1972) in the
French series and in Berne about unity (Job et al., 1972; Francois et al., 1974; Joss, 1975), and in Holland $0 \cdot 7$ (R. Steendijk, personal communication, 1976). One cause of this variation is likely to be differences in ascertainment of cases. It is noticeable that in the early days of growth hormone treatment in a country the ratio of IGHD to MPHD cases is low; in the 1968 report of the San Francisco group (Goodman et al., 1968) it was $0 \cdot 8$, a situation which had greatly changed by 1974 . The prevalence of ascertained cases at present varies greatly from country to country; for example, about the same absolute number of cases have been treated in Holland (population $14 \mathrm{~m}$ ) as in Canada (population $20 \mathrm{~m}$ ) at the time of writing. The percentage of familial cases and of breech births also varies widely, though the sex ratio varies little (see below). It is likely that both pathology and aetiology differ in the various samples of cases and our title stresses the fact that we have studied aetiology in England and Wales only, with the implication that the same mixture of factors may not altogether apply to cases elsewhere. It is perhaps relevant to remark that other samples may in part have been influenced by local difficulties in the provision of treatment. Such difficulties would tend to lead to preferential ascertainment of the severest cases, which in general are those with multiple deficiency. We have been fortunate in having been able to offer treatment to all cases shown to have GHD.

Both environmental and genetic factors are concerned in the aetiology of the condition. We could ascribe no significant effects to month of birth, social class, or parental age. Birthweights of the affected children were normal. There was no excess of perinatal deaths, miscarriages, or complications during pregnancy with the exception of reported vaginal bleeding, which was significantly increased especially before the 27 th postmenstrual week. The pregnancies producing unaffected sibs did not show this feature.

There was a highly significant excess of first-borns, breech deliveries, and forceps deliveries, the last both in first-borns and later-borns but especially in the later-born. Evidently a difficult birth contributed to the chances of developing the GHD. Furthermore, the incidence of abnormal births was higher in cases of MPHD than in IGHD and this may support the notion that one is simply a more severe form of the other. Breech delivery was the most important of the three factors; it occurred in $19 \cdot 0 \pm 8 \cdot 5 \%$ of MPHD cases and $10 \cdot 2 \pm 2 \cdot 8 \%$ of the IGHD cases. The same has been noted in several other series; the findings are summarized in Table 8. Pooling such probably disparate studies is scarcely justified, but it is worth noting that the range of mean incidences in the 
Table 8 Frequency of breech delivery in various reports

\begin{tabular}{|c|c|c|c|c|c|c|c|}
\hline \multirow{2}{*}{ Author } & \multirow{2}{*}{ Country } & \multicolumn{2}{|c|}{ 'Isolated' GHD } & \multicolumn{2}{|c|}{ Multiple PHD } & \multicolumn{2}{|c|}{ Isolated + multiple } \\
\hline & & Cases & $\%$ breech & Cases & $\%$ breech & Cases & $\%$ breech \\
\hline $\begin{array}{l}\text { Goodman et al. (1968) } \\
\text { Job et al. (1972) } \\
\text { Francois et al. (1974) } \\
\text { Joss (1975) } \\
\text { Rona \& Tanner (1977) }\end{array}$ & $\begin{array}{l}\text { USA } \\
\text { France } \\
\text { France } \\
\text { Switzerland } \\
\text { England \& Wales }\end{array}$ & $\begin{array}{r}16 \\
11 \\
10 \\
12 \\
119\end{array}$ & $\begin{array}{r}0 \cdot 0 \\
9 \cdot 1 \\
10 \cdot 0 \\
8 \cdot 3 \\
10 \cdot 1\end{array}$ & $\begin{array}{l}19 \\
20 \\
11 \\
14 \\
21\end{array}$ & $\begin{array}{l}21 \cdot 1 \\
75 \cdot 0 \\
54 \cdot 5 \\
50 \cdot 0 \\
19 \cdot 0\end{array}$ & $\begin{array}{r}35 \\
31 \\
21 \\
26 \\
140\end{array}$ & $\begin{array}{l}11 \cdot 4 \\
51 \cdot 6 \\
33 \cdot 3 \\
30 \cdot 7 \\
11 \cdot 4\end{array}$ \\
\hline Average & & 168 & $8 \cdot 9$ & 85 & $42 \cdot 3$ & & \\
\hline $\begin{array}{l}\text { Bierich (1972) } \\
\text { Guyda et al. (1975) } \\
\text { O. Trygstad, personal } \\
\text { communication (1976) }\end{array}$ & $\begin{array}{l}\text { W. Germany } \\
\text { Canada } \\
\text { Norway }\end{array}$ & & & & & $\begin{array}{r}45 \\
119 \\
36\end{array}$ & $\begin{array}{r}48 \cdot 9 \\
1.7 \\
0.0\end{array}$ \\
\hline Overall average & & & & & & 453 & $16 \cdot 5$ \\
\hline Brasel et al. (1965) & \multicolumn{7}{|c|}{ No mention of breech delivery in 45 cases } \\
\hline
\end{tabular}

IGHD cases is $0-10 \%$ while that in the MPHD cases is $19-75 \%$.

The significance of this high proportion of breech deliveries is not completely clear. Joss (1975) simply writes, 'Our results leave no doubt that birth injury is the main aetiological factor to be considered in the case of idiopathic GHD.' Job et al. (1972) reported an increased amount of fetal distress in their cases, and Prader et al. (1967) said that nearly all their patients had suffered trauma or asphyxia at birth. Our finding that forceps delivery, especially in multiparae, is also associated with an increased incidence of GHD supports this interpretation. So does the fact that the mean height of our mothers was only at the 35th centile for the population whereas those of fathers and unaffected sibs were at the 50th. The distribution of mothers' height has shifted as a whole; there were no pathologically small mothers in this sample. It is well-known that small mothers have a higher proportion of babies suffering birth trauma, and selection by results of such trauma would lead to reduction in the mean height of our mothers.

However, it must be remembered that breech delivery accompanies several other abnormalities and some of them appear well before birth. Braun et al. (1975) reviewed several mechanisms which lead to failure of vertex positioning at delivery. These include malimplantation of the placenta (Brenner et al., 1974), an aberrant shape of the uterine cavity, and lack of constraint by the uterus to fetal positioning. The excess of reported early vaginal bleeding, if confirmed in other studies, might suggest malimplantation. The problem is to know whether the fetus was normal before delivery started. In birthweight the GHD cases are indeed normal, but in one respect some at least appear to be affected before birth. A substantial proportion of male patients have abnormally short penises though no hypospadias (Laron and Sarel, 1970; Tanner et al., 1971). This argues a lack of testosterone secretion by the fetus during the second trimester of pregnancy and hence a failure of secretion either of luteinizing hormone by the fetal pituitary or of human chorionic gonadotrophin by the chorion at that time. So far as the effect of breech delivery is concerned the problem may well be clarified in the near future, since it is now the practice of a number of centres to deliver their babies by caesarean section. If a major contributory factor to GHD is really simply birth trauma, then the incidence in these caesareans should be no higher than that in vertex presentations of caesareans in general.

There is little information in the literature about forceps delivery. In our series forceps in multiparae was associated with a risk of developing GHD $2 \cdot 1$ times greater than usual (in the average year of birth of our cases), and the incidence of forceps was twice as high in MPHD as in IGHD. This points both to something about the delivery itself being abnormal (unless it was really done at the whim of the obstetrician or is fully accounted for by the small size of the mother) or to damage being caused by the manipulation involved. It does not distinguish between the two.

The literature has also little to say about the relative incidence in first- and later-born children. The relative risk, independent of breech or forceps delivery, is only 1.3 and it is arguable that the generally greater risk of birth trauma in first-borns accounts for this.

Sex. Birth trauma seems less likely to account for the large excess of males suffering from GHD. Sex exerted an effect independent of breech or forceps delivery. Thus breech delivery in a girl added just as much excess risk to her small basic risk of being 
Table 9 Sex ratio in idiopathic $G H$ deficiency

\begin{tabular}{|c|c|c|c|c|c|c|c|}
\hline \multirow{2}{*}{ Author } & \multirow{2}{*}{ Country } & \multicolumn{2}{|c|}{ 'Isolated' GHD } & \multicolumn{2}{|c|}{ Multiple PHD } & \multicolumn{2}{|c|}{ Isolated + multiple } \\
\hline & & Cases & Ratio & Cases & Ratio & Cases & Ratio \\
\hline $\begin{array}{l}\text { Prader et al. (1967) } \\
\text { Goodman et al. (1968) } \\
\text { Job et al. (1972) } \\
\text { Francois et al. (1974) } \\
\text { Joss (1975) } \\
\text { Rona \& Tanner (1977) }\end{array}$ & $\begin{array}{l}\text { Switzerland } \\
\text { USA } \\
\text { France } \\
\text { France } \\
\text { Switzerland } \\
\text { England \& Wales }\end{array}$ & $\begin{array}{r}12 \\
16 \\
11 \\
10 \\
12 \\
177\end{array}$ & $\begin{array}{l}2 \cdot 0 \\
1 \cdot 0 \\
1 \cdot 2 \\
1 \cdot 0 \\
1 \cdot 4 \\
4 \cdot 1\end{array}$ & $\begin{array}{r}3 \\
19 \\
20 \\
11 \\
14 \\
31\end{array}$ & $\begin{array}{l}\text { All male } \\
2 \cdot 8 \\
9 \cdot 0 \\
2 \cdot 7 \\
6 \cdot 0 \\
2 \cdot 9\end{array}$ & $\begin{array}{r}15 \\
35 \\
31 \\
21 \\
26 \\
208\end{array}$ & $\begin{array}{l}2 \cdot 7 \\
1 \cdot 7 \\
3 \cdot 4 \\
1 \cdot 6 \\
1 \cdot 7 \\
3 \cdot 8\end{array}$ \\
\hline Average & & 238 & $\mathbf{3 \cdot 0}$ & 98 & $3 \cdot 9$ & & \\
\hline $\begin{array}{l}\text { Brasel et al. (1965) } \\
\text { Bierich (1972) } \\
\text { Aceto et al. (1974) } \\
\text { Guyda et al. (1975) } \\
\text { Trygstad (1976) } \\
\text { Steendijk (1976) }\end{array}$ & $\begin{array}{l}\text { USA } \\
\text { W. Germany } \\
\text { USA } \\
\text { Canada } \\
\text { Norway } \\
\text { Holland }\end{array}$ & & & & & $\begin{array}{r}45 \\
45 \\
112 \\
119 \\
36 \\
95\end{array}$ & $\begin{array}{l}3 \cdot 1 \\
3 \cdot 5 \\
2 \cdot 5 \\
2 \cdot 7 \\
1 \cdot 4 \\
3 \cdot 1\end{array}$ \\
\hline Overall average & & & & & & 788 & $2 \cdot 9$ \\
\hline
\end{tabular}

GHD as it added to the greater basic risk in a boy. Table 9 gives the sex ratio of series reported in the literature. The various series are consistent, with an overall ratio of 2.9 boys to 1 girl. There is a slight tendency for the sex ratio to be lower in IGHD than in MPHD.

Genetic factors. The great majority $(97 \%)$ of our affected children were the only cases in their family. However, about $4.5 \%$ of their brothers, $2 \%$ of fathers, $1.5 \%$ of sisters, and $1.5 \%$ of mothers were themselves GHD. Most authors report some familial cases, and our experience seems fairly typical. The only exception is in Norway, where $30 \%$ of cases reported during 1961-71 were familial (Seip, et al., 1971). Naturally a quite different picture is obtained if familial cases, especially of adults, are specifically searched for, as in the study of Rimoin et al. $(1966,1968)$. Most of the familial cases have true isolated GHD, but MPHD has also been reported in familial form (Trygstad and Seip, 1964; Rimoin et al., 1968; Joss, 1975).

Though the family histories of individual cases are frequently compatible with various forms of single gene inheritance, the population statistics rule out any such simple explanation for the disorder as a whole. However, the possibility exists that there are two entirely different sorts of cases, the familial and those caused by birth or other trauma. If so, the genetic cases are suspiciously heterogeneous in terms of family history. $\mathbf{3}$ of our $\mathbf{4}$ families were compatible with the single gene autosomal recessive inheritance favoured by the majority of pedigrees in Bierrich (1964), Seip et al. (1968), Moe (1968), Rimoin et al. (1968), and Kamahara et al. (1972). But one of the 4 families contained an affected parent and 2 affected children, a pattern also seen in the families reported by Butenandt and Knorr (1970), Sheikholislam and
Stempfel (1972), Sadeghi-Nejad and Senior (1974), and Poskitt and Rayner (1974). To explain these pedigrees on the hypothesis of single-locus autosomal recessive inheritance it would be necessary to postulate marriages between affected homozygotes and normal heterozygote carriers. The probability of such matings is very small where a rare gene is involved, and in these families a dominant form of inheritance is more likely. There was no inbreeding in our families, nor in most others reported, though both of Joss's (1975) two sibships were products of cousin marriages, and McKusick and Rimoin (1967) found frequent inbreeding in the families they ascertained. Few of the familial cases seem to have suffered birth trauma, though out of Joss's (1975) 5 cases one was delivered by breech and one by forceps.

We propose a different theory of aetiology, that there is a susceptibility which is inherited polygenically and which is acted upon by exciting factors, primarily birth trauma and perhaps infection of the fetus and its membranes, to produce a liability to the clinical disease. This model is well known as an explanation for a number of disorders and malformations, such as cleft lip and palate, anencephaly, and pyloric stenosis (see Carter, 1976). Idiopathic GHD would thus take its place as one of the rarer single congenital malformations.

The genetic model for these defects (explained with precision and elegance in Cavalli-Sforza and Bodmer, 1971) is chiefly known through the work of Falconer (1965-66) and Edwards (1969). It assumes that behind the disorder there is an underlying quantity, called liability, continuously distributed in a given population (like height or blood pressure). Persons in whom this liability is greater than a fixed value, called the threshold, manifest the malformation (cleft lip and palate, say) or become diagnosable 
as persons with the disorder (idiopathic GHD, that is short stature plus lack of $\mathrm{GH}$ secretion on provocative test). Thus two classes of persons are manifested, the affected and the nonaffected, but only because of a diagnostic threshold which may be less (cleft palate) or more (GHD) arbitrary. A population consisting of first degree relatives of affected persons has a higher average value for liability than the population at large, because its members have a higher proportion of the genes underlying the character called liability. The amount by which being a relative increases the liability value measures the heritability of the disorder, assuming that no significant gene-environment interactions occur.

Graphs have been constructed by which the heritability may be estimated, given values for the incidence of the disorder in the general population and the incidence in relatives of the affected (CavalliSforza and Bodmer, 1971). In view of the sex difference in incidence of GHD the calculations have to be made for each sex singly (though the results obtained from each sex agree). The incidence of GHD in first-degree male relatives (brothers and fathers) of affected males is $2-4 \%$ in world data at present. The incidence of affected males in the general population of males is much more difficult to estimate, but probably lies between 1 in 5000 and 1 in 30000 births and we think nearer the former. Taking the values $3 \%$ and 1 in 10000 gives a heritability of $90 \%$. This puts idiopathic GHD in the same heritability class as coeliac disease, anencephaly, pyloric stenosis, and patent ductus.

It is important to realize what heritability does and does not mean in this context. The term was introduced to quantify the force of selection in animal breeding; it measures the rapidity with which we could achieve a population of GHD persons through selecting GHD individuals for breeding. It does not mean that the genes are $90 \%$ responsible for the condition; on the contrary, the underlying liability is the sum of both genetic and environmental effects.

The polygenic threshold model regards IGHD and MPHD as facets of the same disease. When the liability just reaches the threshold we would presume IGHD results; the further beyond the threshold liability gets the greater the likelihood of developing MPHD. If this is so, then in a few families there should be a mixture of types of case (cf Smith, 1975-76). This did not occur in any of our 4 reported families, but it did in one referred to us since this study was begun, as well as in one of Joss's (1975) 2 families.

Thus it seems to us there are two points of view as to the aetiology of GHD. They may be called the 'lumping' and 'splitting' views. The lumping view is that described above; it regards IGHD and MPHD as a single disease with polygenicallycontrolled susceptibility interacting with environmental pathogenic causes to give the minor or major aspect of the disease. The 'splitter' view is that the disorder consists of familial cases, probably of quite simple genetic causation, cases due to birth trauma, and perhaps cases due to some other environmental or intrauterine insult. The Fig. shows a hypothetical model of the genesis of cases; it does not distinguish between these two points of view.

Population Screening. The present study allows estimates to be made of the relative risk for a given newborn to have GHD (Table 10). Three factors are

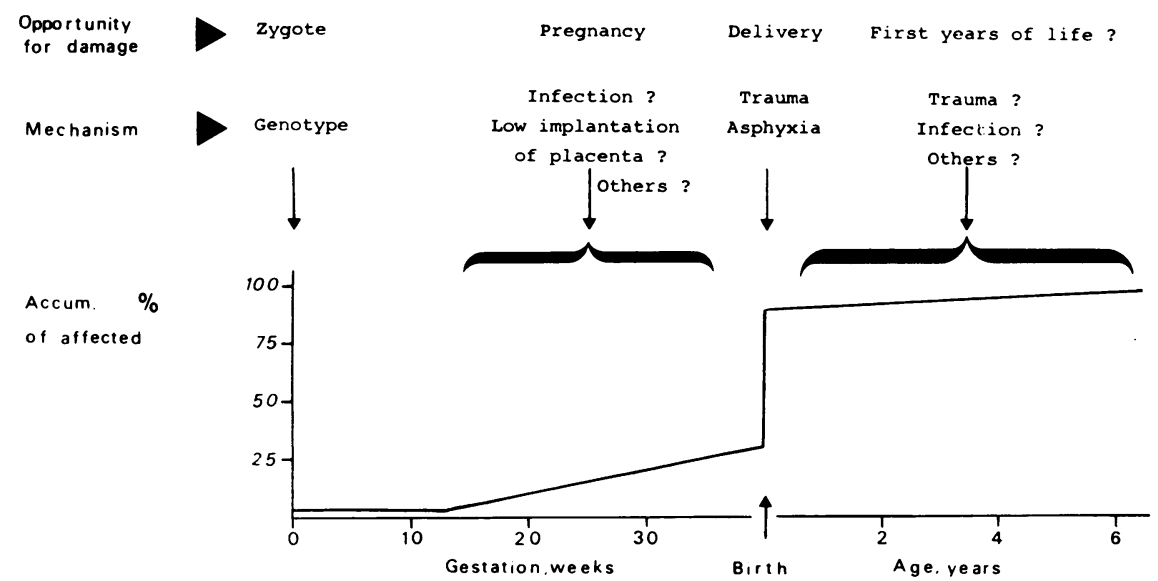

Fig. Hypothetical model of accumulation of cases of idiopathic GHD at various ages. Vertical scale gives estimated proportion of total cases developed at each period. 
Table 10 Risk of idiopathic GHD (affected/nonaffected)

\begin{tabular}{lrl}
\hline Group & Risk & $\begin{array}{l}\text { Confidence } \\
\text { Limits }\end{array}$ \\
\hline Male-Breech-Primip & $11 \cdot 3$ & $4 \cdot 9-26 \cdot 0$ \\
Male-Breech-Multip & $8 \cdot 5$ & $3 \cdot 7-19 \cdot 6$ \\
Male-Forceps-Multip & $8 \cdot 7$ & $2 \cdot 8-26 \cdot 7$ \\
Female-Breech-Primip & $5 \cdot 0$ & $1 \cdot 7-15 \cdot 2$ \\
Female-Breech-Multip & $1 \cdot 6$ & $0 \cdot 3-8 \cdot 3$ \\
Female-Forceps-Multip & $5 \cdot 1$ & $1 \cdot 0-27 \cdot 4$ \\
Male-Forceps-Primip & $3 \cdot 1$ & $1 \cdot 7-6 \cdot 1$ \\
Male-Vertex*-Primip & $1 \cdot 9$ & $1 \cdot 3-2 \cdot 8$ \\
Male Vertex*-Multip & $1 \cdot 2$ & $0 \cdot 8-2 \cdot 4$ \\
Female-Forceps-Primip & $1 \cdot 4$ & $0 \cdot 5-4 \cdot 2$ \\
Female-Vertex*-Primip & $0 \cdot 4$ & $0 \cdot 2-0 \cdot 8$ \\
Female-Vertex*-Multip & $0 \cdot 2$ & $0 \cdot 1-0 \cdot 4$ \\
\hline
\end{tabular}

*'Vertex' includes caesarean section.

considered: sex of the baby, parity of mother, and method of delivery. The three highest risk groups, at the top of the table, furnish $11 \%$ of the cases and $1.4 \%$ of all deliveries in England and Wales. The seven highest groups give nearly $50 \%$ of all cases and come from $20 \%$ of all deliveries. This table could be used as a basis of a policy of screening. It would be necessary to measure length (or heights after age 2) of the infants at risk and not only weight since weights are much less abnormal, owing to the fatness of GHD infants. An efficient screening of length at 18 months, using the Holtain infantometer, should result in many more cases being diagnosed early than is now the case. In this way treatment would have a better chance of complete success (Tanner, 1975).

We wish to thank Drs. Michael Parkin and Paul Rayner for generous assistance in giving questionnaires to their patients; Dr. Michael Preece for obtaining data on the Medical Research Council Trial patients in centres outside London; Miss Janet Baines for much help in administering the questionnaire and arranging the patients' visits. R. J. R. was supported partly by the World Health Organization Fellowship programme and partly by the Nuffield Foundation.

\section{References}

Aceto, T., Frasier, S. D., Hayles, A. B., Meyer-Bahlburg, H. F. L., Parker, M. L., Munschauer, R., and Di Chiro, G. (1974). Collaborative study of the effects of human growth hormone in growth hormone deficiency. III. First eighteen months of therapy. Advances in Human Growth Hormone Research, p. 695. Ed. by S. Raiti. Publication No. NIH 74-612. Department of Health, Education and Welfare, Washington.

Bailey, J. D., Bain, H. W., Thompson. M. M., Gagliardino, J. J., and Martin, J. M. (1967). Etiological factors in idiopathic hypopituitary dwarfism. (Abstracts of the American Paediatric Society). Pediatric Research, 1, 300-301.
Bierich, J. R. (1964). On genetically determined pituitary dwarfism. Acta Endocrinologica, Suppl. 89, 27

Bierich, J. R. (1972). On the aetiology of hypopituitary dwarfism. Growth and Growth Hormone. Proceedings of the Second International Symposium on Growth Hormone, p. 408. Ed. by A. Pecile and E. E. Müller. Excerpta Medica, Amsterdam,

Brasel, J. O., Wright, J. C., Wilkins, L., and Blizzard, R. M. (1965). An evaluation of seventy-five patients with hypopituitarism beginning in childhood. American Journal of Medicine, 38, 484-498.

Braun, F. H. T., Jones, L. S., and Smith, D. W. (1975). Breech presentation as an indicator of fetal abnormality. Journal of Pediatrics, 86, 419-421.

Brenner, W. E., Bruce, R., and Hendricks, C. H. (1974). The characteristics and perils of breech presentation. American Journal of Obstetrics and Gynecology, 118, 700712.

Butenandt, O., and Knorr, D. (1970). Familiärer hypopituitarismus. Monatsschrift für Kinderheilkunde, 118, 470-473.

Butler, N. R., and Alberman, E. D. (1969). Perinatal Problems. Second Report of the 1958 British Perinatal Mortality Survey. Livingstone, Edinburgh and London.

Butler, N. R., and Bonham, D. G. (1963). Perinatal Mortality. First Report of the 1958 British Perinatal Mortality Survey. Livingstone, Edinburgh and London.

Carter, C. O. (1976). Genetics of common single malformations. British Medical Bulletin, 32, 21-26.

Cavalli-Sforza, L. L., and Bodmer, W. F. (1971). The Genetics of Human Populations, pp. 553-565. Freeman, San Francisco.

Chamberlain, R. (1975). First week of life. British Births 1970, Vol. 1. Heinemann, London.

Crow, J. F. (1965). Problems of ascertainment in the analysis of family data. Genetics and Epidemiology of Chronic Diseases, p. 23. Ed. by J. V. Neel, M. W. Shaw, and W. J. Schull. Publication No. 1963. Department of Health, Education and Welfare, Washington.

Edwards, J. H. (1958). Congenital malformations of the central nervous system in Scotland. British Journal of Preventive and Social Medicine, 12, 115-130.

Edwards, J. H. (1961-62). The recognition and estimation of cyclic trends. Annals of Human Genetics, 25, 83-87.

Edwards, J. H. (1969). Familial predisposition in man. British Medical Bulletin, 25, 58-64.

Falconer, D. S. (1965-66). The inheritance of liability to certain diseases, estimated from the incidence among relatives. Annals of Human Genetics, 29, 51-76.

Fleiss, J. L. (1973). Statistical Methods for Comparing Ratio and Proportions. Wiley, New York.

Francois, R., David, L., and Clerget-Guarnaud, M. (1974). Traitment des nanismes hypophysaires. Pédiatrie, 29, 305-318.

Goodman, H. G., Grumbach, M. M., and Kaplan, S. L. (1968). Growth and growth hormone. II. A comparison of isolated growth hormone deficiency and multiple pituitary hormone deficiencies in 35 patients with idiopathic hypopuitary dwarfism. New England Journal of Medicine, 278, 57-68.

Great Britain. General Register Office (1963). Registrar General's Statistical Review of England and Wales. HMSO, London.

Great Britain. General Register Office. (1969) Registrar General's Statistical Review of England and Wales. HMSO, London.

Great Britain. General Register Office (1971). Registrar General's Statistical Review of England and Wales. HMSO, London. 
Guyda, H., Friesen, H., Bailey, J. D., Lebeouf, G., and Beck, J. C. (1975). Medical Research Council of Canada therapeutic trial of human growth hormone: first 5 years of therapy. Canadian Medical Association Journal, 112, 1301-1309.

Hubble, D. (1967). Growth hormone deficiencies in childhood. Canadian Medical Association Journal, 97, 1144-1158.

Job, J. C., Lejeune, C., Canlorbe, P., and Rossier, A. (1972). Le nanisme par insuffisance hypophysaire sporadique idiopathique. Etude d'une série de 31 cas. Archives Françaises de Pédiatrie, 29, 117-134.

Joss, E. E. (1975). Growth Hormone Deficiency in Childhood: Evaluation of Diagnostic Procedures. Monographs in Paediatrics, No. 5. Karger, Basle.

Kaplan, S. L., Savage, D. C. L., Suter, S., Wolter, R., and Grumbach, M. M. (1974). Antibodies to human growth hormone arising in patients treated with human growth hormone: incidence characteristics and effects on growth. Advances in Human Growth Hormone Research, p. 725. Ed. by S. Raiti. Publication No. NIH 74-612. Department of Health, Education and Welfare, Washington.

Kumahara, Y., Okada, Y., Miyai, K., and Inatsubo, H. (1970). Typical cases of isolated growth hormone deficiency with autosomal recessive inheritance. Acta Endocrinologica, 63, 618-624.

Laron, Z., and Sarel, R. (1970). Penis and testicular size in patients with growth hormone insufficiency. Acta Endocrinologica, 63, 655-633.

McKusick, V. A., and Rimoin, D. L. (1967). General Tom Thumb and other midgets. Scientific American, 217, 102-110.

MacMahon, B., and Pugh, T. F. (1971). Epidemiology: Principles and Methods. Little, Brown, Boston.

Moe, P. J. (1968). Hypopituitary dwarfism. The importance of early therapy. Acta Paediatrica, 57, 300-304.

Neel, J. V., and Schull, W. J. (1964). Human Heredity. University of Chicago Press, Chicago.

Pearson, E. S., and Hartley, M. O. (1966). Biometrika Tables for Statisticians, 3rd ed., Vol. 1. Cambridge University Press, London.

Poskitt, E. M. E., and Rayner, P. H. W. (1974). Isolated growth hormone deficiency. Two families with autosomal dominant inheritance. Archives of Disease in Childhood, 49, 55-59.

Prader, A. (1960). Hypothalamic pituitary dwarfism. Transactions: Club for Paediatric Research Meeting, Groningen.

Prader, A., Zachmann, M., Poley, J. R., Illig, R., and Szeky, J. (1967). Long-term treatment with human growth hormone (Raben) in small doses. Evaluation of 18 hypopuitary patients. Helvetica Paediatrica Acta, 22, 423-440.

Prader, A., Ferrandez, A., Zachmann, M., and Illig, R. (1972). Effect of hGH treatment on growth, bone age and skinfold thickness in 44 children with growth hormone deficiency. Growth and Growth Hormone. Proceedings of the Second International Symposium on Growth Hormone, p. 245. Ed. by A. Pecile and E. E. Müller. Excerpta Medica, Amsterdam.

Rimoin, D. L., Merimee, T. J., and McKusick, V. A. (1966). Growth hormone deficiency in man; isolated, recessively inherited defect. Science, 152, 1635-1637.

Rimoin, D. L., Merimee, T. J., Rabinowitz, D., CavalliSforza, L. L., and McKusick, V. A. (1968). Genetic aspects of isolated growth hormone deficiency. Growth Hormone. Proceedings of the First International Symposium, p. 418. Ed. by A. Pecile and E. E. Müller. Excerpta Medica, Amsterdam.

Rona, R. J. (1976). An epidemiological and genetic study of idiopathic growth hormone deficiency. Ph.D. thesis, University of London.

Rosenbloom, A. L., and Smith, D. W. (1965). Idiopathic anterior hypopituitarism in one of identical twins. Journal of Pediatrics, 67, 84-88.

Sadeghi-Nejad, A., and Senior, B. (1974). Autosomal dominant transmission of isolated growth hormone deficiency in iris-dental dysplasia (Rieger's Syndrome). Journal of Pediatrics, 85, 644-648.

Seip, M., Van der Hagen, C. B., and Trygstad, O. (1968). Hereditary pituitary dwarfism with spontaneous puberty. Archives of Disease in Childhood, 43, 47-52.

Seip, M., Trygstad, O., and Aarskog, D. (1971). Comment on pituitary dwarfism in Norway, 1961-1970. Birth Defects, Original Article Series, Vol. 7, No. 6, 33-34.

Sheikholislam, B. M., and Stempfel, R. S. (1972). Heredity isolated somatotropin deficiency: effect of human growth hormone. Pediatrics, 49, 362-374.

Smith, C. (1975-76). Statistical resolution of genetic heterogeneity in familial disease. Annals of Human Genetics, 39, 281-291.

Tanner, J. M. (1975). Toward complete success in the treatment of growth hormone deficiency; a plea for earlier ascertainment. Health Trends, 7, 61-64.

Tanner, J. M., and Thomson, A. M. (1970). Standards for birthweight at gestation periods from 32 to 42 weeks, allowing for maternal height and weight. Archives of Disease in Childhood, 45, 566-569.

Tanner, J. M., and Whitehouse, R. H. (1975). A note on the bone age at which patients with true isolated growth hormone deficiency enter puberty. Journal of Clinical Endocrinology and Metabolism, 41, 788-790.

Tanner, J. M., Whitehouse, R. H., and Takaishi, M. (1966). Standards from birth to maturity for height, height velocity and weight velocity: British children. Archives of Disease in Childhood, 41, 454-471 and 613-635.

Tanner, J. M., Whitehouse, R. H., Hughes, P. C. R., and Vince, F. P. (1971). The effect of human growth hormone treatment for 1 to 7 years on the growth of 100 children, with growth hormone deficiency, low birthweight, inherited smallness, Turner's syndrome and other complaints. Archives of Disease in Childhood, 46, 745-782.

Tanner, J. M., Lejarraga, H., and Cameron, N. (1975). The natural history of the Silver-Russell syndrome. A longitudinal study of thirty-nine cases. Pediatric Research, 9, 611-623.

Trygstad, O., and Seip, M. (1964). Hereditary pituitary dwarfism treated with human growth hormone. Acta Paediatrica, 53, 527-532.

Walter, S. D., and Elwood, J. M. (1975). A test for seasonability of events with a variable population at risk. British Journal of Preventive and Social Medicine, 29, 18-21.

Correspondence to Professor J. M. Tanner, Department of Growth and Development, Institute of Child Health, 30 Guilford Street, London WC1N $1 \mathrm{EH}$. 